\title{
Inhaltsverzeichnis/Table of Contents
}

Hinweise für den Benutzer . . . . . . . XI Abkürzungen . . . . . . . . . XV Literaturauswahl . . . . . . . . XVII

Sachgruppenübersicht

1. Bibliografien, Bibliothekskataloge . . . 3

2.Zeitungen, Periodika ........ 4

3. Allgemeines, Reisebeschreibungen . . . 7

4. Religion, Philosophie, Psychologie . 21

a. Allgemeines ......... 21

b. Buddhismus ......... . 26

c. Shinto ........... 31

d.Christentum ......... 32

5. Bildende Kunst, Kunsthandwerk . . 37

6. Musik, Tanz, Theater . . . . . . . . 55

7. Sport, Spiele, Freizeit . . . . . 57

8. Sprache, Schrift . . . . . . . 66

a. Allgemeines, Spezialuntersuchungen 66

b. Lehrbücher, Grammatiken . . . . . 68

c. Wörterbücher, Zeichenlexika . . 69

9. Literatur . . . . . . . . . . . 71

a. Allgemeines, Spezialuntersuchungen 71

b. Übersetzungen . . . . . . . . . . . 74

c. Japan in der deutschsprachigen

Literatur, Japonismus . . . . . . 85

10. Volks- und Völkerkunde, Märchen . . 100

11. Geografie . . . . . . . . . . . . 104

a. Karten und Atlanten . . . . . 104

b.Sonstiges . . . . . . . . . 106

12. Geschichte . . . . . . . . . 109

a. Allgemeines, mehrere Epochen . . 109

b. bis $1600 \ldots \ldots 113$

c. Edo-Zeit (1603-1867) . . . . . 113

d. Meiji-Zeit (1868-1912) . . . . 114

e. $1912-1920 \ldots \ldots$. . . . . . 116

f. 1921-1970 . . . . . . . 117

- Amerika und Japan . . . . . 117

- China und Japan . . . . . . . 118

- Deutschland und Japan . . . . 120

- Korea und Japan . . . . . . . . . 121

- RuBland und Japan . . . . . 121

- Thailand und Japan . . . . . . . 122

- Pazifischer Krieg (1941-1945) . 122

g. 1912- ............ 131

13. Politik, Gesellschaft . . . . . . 131

14. Militär . . . . . . . . . . . 144
Explanatory Notes . . . . . . . . . XIII

List of Abbreviations . . . . . . . XV

Main Bibliographic Sources ...... XVII

Subject Guide

1. Bibliographies, Library Catalogues . . 3

2. Newspapers, Periodicals . . . . . . . 4

3. General, Travel Books . . . . . . . 7

4. Religion, Philosophy, Psychology 21

a. General . . . . . . . . . 21

b. Buddhism 26

c. Shinto . . . . . . . . 31

d. Christian religion ..... 32

5. Fine arts, Arts and Crafts $\quad 37$

6. Music, Dance, Theater . . . . . . . 55

7. Sports, Games, Leisure 57

8. Language, Script . . . . . . . . . 66

a. General, Special Research . . . 66

b. Textbooks, Grammars $\quad 68$

c. Dictionaries . . . . . . . . . . 69

9. Literature . . . . . . . . . . . 71

a. General, Special Research . . . . 71

b. Translations . . . . . . . . . . 74

c. Japan in German-language

Literature, Japonism . . . . . . . . 85

10. Folklore and Ethnology, Fairy Tales . 100

11. Geography . . . . . . . . . . 104

a. Maps and Atlases . . . . . . . . 104

b. Other . . . . . . . . . 106

12. History . . . . . . . . . . 109

a. General, Several Eras . . . . . 109

b. Until 1600 . . . . . . . . . . . 113

c. Edo Period (1603-1867) . . . . 113

d. Meiji Era (1868-1912) . . . . . . 114

e. $1912-1920 \ldots \ldots$. . . . . . 116

f. $1921-1970 \ldots \ldots 117$

- America and Japan . . . . 117

- China and Japan . . . . . . . 118

- Germany and Japan . . . . . . 120

- Korea and Japan . . . . . . . . 121

- Russia and Japan . . . . . . . . 121

- Thailand and Japan . . . . . 122

- Pacific War (1941-1945) . . . 122

g. 1912- . . . . . . . . . 131

13. Politics, Society . . . . . . . . 131

14. Military Affairs . . . . . . . . 144 
15. Recht, Verwaltung . . . . . . . . 145

15. Law, Administration . . . . . . . 145

16. Bildung, Wissenschaft, Kultur, Presse 147

16. Education, Science, Culture, Press . . 147

17. Wirtschaft, Finanzen, Verkehr . . . 150

18. Land- und Forstwirtschaft, Fischerei,

17. Economy, Finance,

Ernährung ......... 161

19. Naturwissenschaft, Technik _ . . 162

20. Medizin . . . . . . . . . 165

Verfasser-, Titel- und Stichwort-

Transportation . . . . . . 150

Register . . . . . . . . . . . . 169

18. Agriculture, Forestry, Fishery, Food . 161

19. Natural Science, Engineering

Science . . . . . . . . . . 162

20. Medicine ........... . 165

Author-Title-Keyword Index . . . . . . 169 